\title{
Overvoltage Effects on Ground Grid Systems of Single and Two Neighboring High Voltage Substations
}

\author{
Krung Luewattana, Aphibal Pruksanubal \\ Department of Electrical Engineering, Faculty of Engineering, King Mongkut's University of Technology North \\ Bangkok, Thailand
}

\section{Article Info}

\section{Article history:}

Received May 27, 2016

Revised Jul 4, 2016

Accepted Jul 18, 2016

\section{Keyword:}

Ground gridsystem Ground potential rise High voltage substation Overvoltage

\begin{abstract}
The power networkswith reliable transmission and distribution systems require high voltage substations with effective ground grid systems. Therefore, this study aimed to analyze the effects of overvoltage on ground grid systems within high voltage substations in two cases, including a single substation and the two neighboring substations, by using ATP/EMTP and ANSYS softwares. The simulations were performed to show both plotting graphs and 3D results when the fault current flowed into the ground grids of substations at various positions. In case of the single highvoltage substation, the overvoltage was highest when the fault current was injected at the corner of ground grid. However, in case of two neighboring high voltage substations, the levels of overvoltage were similar between that caused by injecting the fault current at the center and at the corner of ground grid. The simulation showed that overvoltage which occurring at the ground grid of high voltage substation A could permeate to the ground grid of nearby high voltage substation $B$, which nevertheless depending on the how the fault current was injected at different spots. The data from these simulations and analysis can be useful for future designs of ground grid systems with high reliability.
\end{abstract}

Copyright $@ 2016$ Institute of Advanced Engineering and Science. All rights reserved.

\section{Corresponding Author:}

Aphibal Pruksanubal,

Department of Electrical Engineering, Faculty of Engineering,

King Mongkut's University of Technology North Bangkok,

Pibulsongkram Rd., Bangsue, Bangkok, Thailand.

Email: zaraburi@yahoo.com

\section{INTRODUCTION}

Nowadays, electricity is greatly important for national development in several aspects. Initially, when the power energy is generated, it will be transmitted and distributed from the power plants to domestic users via high voltage substations. If the high voltage substations were performed with high reliability, they can transfer electrical power efficiently and safely. Indeed, the reliability of high voltage equipment tremendously depends on the efficiency of the ground grid systems which can prevent the substations' damages due to overvoltage caused by the fault current or the natural disasters, such as lightning strikes. If the ground grid systems are not correctly designed, the fault current will not be effectively distributed to the ground via ground grids. This may result in releasing of a large amount of residual overvoltage that can cause enormous damages to the high voltage equipment in the systems, the person(s) in the vicinity of grounded facilities, and also the systems in neighboring substations [1].

In 1994, EMTP was used to study and analyze the model of ground grid system. In this study, the simulation analysis of the lightning protection system as well as the dynamic behavior of overvoltage occurring on ground system via transmission line model was performed, and the results of simulations were compared to that of calculations in term of ground potential rise (GPR) [2]. Additionally, in 1996, the impacts of overvoltage in a large grounding system were simulated by using EMTP program. The 
comparisons of overvoltage in various injection points were shown [3]. In 2001, a grounding system of transmission line was modeled and studied by using ATP/EMTP. The effects of overvoltage at different points on the ground grids were analyzed according to the differences of grid sizes, diameters of conductor, skin effects, and also permittivity and resistivity of soil [4]. In 2003, the response time of ground rod impulse was studied by creating a model of double exponential time function using EMTP, which was developed from the inverse fast Fourier transformation (IFFT). This was applied to study the dynamic of lightning protection ground and the effects of charge that dispersing into the ground [5]. In 2005, the transient, caused by lightning on transmission line, on grounding system was simulated by using finite difference time domain (FDTD) method. The results were depended on the differences of conductor lengths and ground grid's sizes [6]. Recently, Current Distribution in Earth and Grounding System (CDEGS) program has been used for illustrating the three-dimentional (3D) plots ofpower plant grounding system that was exposed to the lightning current. The results suggested that the spatial distributions of the scalarpotentials and the electric fields werelargely affected [7]. In addition, the severity of lightning strikeon transmission line tower andnearby gas pipeline was explored by using Power System Computer Aided Design (PSCAD) and CDEGS programs, and CDEGS could give more precise results of the effect of soil structure on induced voltage [8].

Therefore, this research aimed to analyze the effects of overvoltage on ground grid systems of high voltage substations by examining the overvoltage occurring at various positions of the ground grid systems in two cases, single and two neighboring substations. The overvoltage that occurred at various positions was simulated and observed by using alternate transient program (ATP)/electromagnetic transients program (EMTP) software. Most importantly, the distribution patterns of electric field on the ground grid systems were also analyzed in 3-D by using ANSYS (Maxwell 3D) software.

\section{RESEARCH METHOD}

\subsection{Substation Grounding System}

The ground grid systems of high voltage substations are particularly important for preventing the substations from any damages caused by fault current or transient, especially which may affect the staffs and a variety of equipment inside the substations. The ground grid system includes all the interconnection grounding facilities, for example, overhead ground wires, ground grids, neutral conductors, and underground cables [9].

Figure 1 showed a case study of square ground grid that was designed according to the standard IEEE Std. 80-2000 [10]. Its dimension was $18 \times 18$ meters which containing 45 ground rods. The ground grid was buried 0.5 meter under soil surface. The soil resistivity was $10 \Omega-\mathrm{m}$. The resistance of the surface material layered at thickness of $0.1 \mathrm{~m}$ was $3000 \Omega-\mathrm{m}$. The conductor's cross sectional area was $95 \mathrm{~mm} 2$. The length of each ground rod was 3 meters. In addition, the fault current at $20 \mathrm{kA}$ magnitude was designated to flow through the conductor.

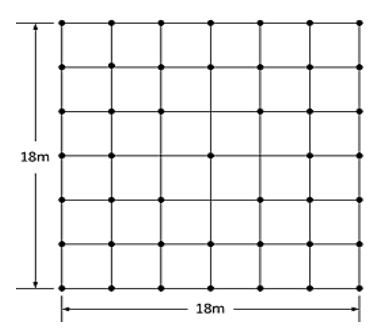

Figure 1. Square Ground Grid System With Ground Rods for Single Substation

\subsection{Definitions of Tolerable Voltage \\ 2.2.1. Fault Current Division Factor}

Fault current division factor is a factor that showing the inversed ratio of the symmetrical fault current to that portion of the current which flowing between the ground grid and the neighboring soil.

\subsubsection{Maximum Grid Current}

Maximum grid current is the multiplication between the decrement factor for the entire duration of fault and rms symmetrical grid current. It can also be calculated by multiplication between the decrement factor for the entire duration of fault and zero-square fault current. 


\subsubsection{Ground Potential Rise (GPR)}

GPS is the maximum electrical voltage that reaches to a substation's ground grid. It is calculated in relative to a distance of grounding point by multiplication between maximum grid current and resistance of grounding system.

\subsubsection{Step Voltage}

Step voltage is the difference of surface voltage between the feet of a person who walking or standing in high voltage substation during the occurrence of fault current. Step voltage is calculated in the distance of $1 \mathrm{~m}$. between the feet.

\subsubsection{Touch Voltage}

Touch voltage is the difference between the rising ground voltage and the surface voltage where a standing person touches a grounded structure.

\subsection{Laydown Material on Soil Surface inside Substation}

The paving surface inside substation must contain thematerials with high resistance in order to increase the resistance between the person's feet and the layered surface and also to prevent the damages from touch voltage and step voltage. The standard IEEE Std.80-2000 recommends that the layer of gravels on the surface should be 8-15 cm thick [10]. Moreover, the Metropolitan Electricity Authority (MEA) and the Provincial Electricity Authority (PEA) generally scatter the gravels on soil surface for about 10-20 cm thick, which was also used in this study as shown in Figure 2.

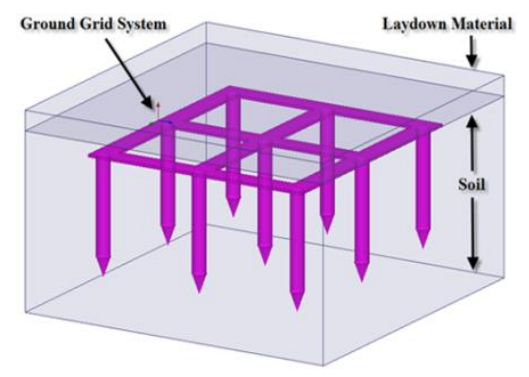

Figure 2. Ground Grid System with Sprinkled Laydown Material

\subsection{Design of Equations for Grounding Grids}

The resistance of grounding system of high voltage substation, the maximum GPR and the other important parameters could be calculated by the following steps:

Firstly, the maximum grid current was calculated by the equations 1 and 2 as following:

$$
\begin{aligned}
& I_{G}=D_{f} \cdot I_{g} \\
& I_{G}=D_{f} \cdot S_{f} \cdot 3 I_{o}
\end{aligned}
$$

From that, the fault current division factor could be obtained by the equation 3 as following:

$$
S_{f}=\frac{I_{g}}{3 . I_{o}}
$$

Then, the ground potential rise (GPR) could be calculated by multiplication between the maximum grid current and the resistance of grounding system as shown in the equation 4 . The resistance of grounding system could be obtained by the equation 5 as following:

$$
\begin{aligned}
& G P R=I_{G} \cdot R_{g} \\
& R_{g}=\rho\left[\frac{1}{L_{T}}+\frac{1}{\sqrt{20 A}}\left(1+\frac{1}{1+h \sqrt{\frac{20}{A}}}\right)\right]
\end{aligned}
$$


The tolerable step voltage for human with body weight of 50 and $70 \mathrm{~kg}$ and the tolerable touch voltage for human with body weight of $50 \mathrm{~kg}$ were then be calculated by equations $6-7$ and $8-9$, respectively, as following:

$$
\begin{aligned}
& E_{\text {step } 50}=\left(1,000+6 C_{s} \cdot \rho_{s}\right) \frac{0.116}{\sqrt{t_{s}}} \\
& E_{\text {step } 70}=\left(1,000+6 C_{s} \cdot \rho_{s}\right) \frac{0.157}{\sqrt{t_{s}}} \\
& E_{\text {touch } 50}=\left(1,000+1.5 C_{s} \cdot \rho_{s}\right) \frac{0.116}{\sqrt{t_{s}}} \\
& E_{\text {touch } 70}=\left(1,000+1.5 C_{s} \cdot \rho_{s}\right) \frac{0.157}{\sqrt{t_{s}}}
\end{aligned}
$$

The mesh voltage and the step voltage could be calculated by the equations 10 and 11 as following:

$$
\begin{aligned}
& E_{m}=\frac{\rho \cdot K_{m} \cdot K_{i} \cdot I_{G}}{L_{m}} \\
& E_{S}=\frac{\rho \cdot K_{s} \cdot K_{i} \cdot I_{G}}{L_{s}}
\end{aligned}
$$

The symbols and definitions for all the above equations were described as below:

$\mathrm{A}=$ area of ground grids $\left(\mathrm{m}^{2}\right)$

$S_{f}=$ fault current division factor

$I_{g}=$ rms symmetrical grid factor

$I_{0}=$ zero-sequence fault current

$I_{G}=$ maximum rms current flowing between ground grid and earth (A)

$D_{f}=$ decrement factor for the entire duration of fault $t_{f}$ (s)

$\mathrm{GPR}=$ ground potential rise $(\mathrm{V})$

$R_{g}=$ resistance of grounding system $(\Omega)$

$E_{\text {Step } 50}=$ tolerable step voltage for human with $50 \mathrm{~kg}$ body weight $(\mathrm{V})$

$E_{\text {Step } 70}=$ tolerable step voltage for human with $70 \mathrm{~kg}$ body weight $(\mathrm{V})$

$E_{\text {touch } 50}=$ tolerable touch voltage for human with $50 \mathrm{~kg}$ body weight (V)

$E_{\text {touch } 70}=$ tolerable touch voltage for human with $70 \mathrm{~kg}$ body weight (V)

$C_{S}=$ surface layer derating factor

$\rho_{s}=$ surface layer resistivity $(\Omega . \mathrm{m})$

$\mathrm{t}_{s}=$ duration of shock current frequency (s)

$E_{m}=$ mesh voltage $(\mathrm{V})$

$\rho=$ average soil resistivity $(\Omega . \mathrm{m})$

$K_{m}=$ mesh factor defined for $\mathrm{n}$ parallel conductors

$K_{i}=$ corrective factor for current irregularity

$L_{m}=$ effective length of $L_{C}+L_{R}$ for mesh voltage (m)

$L_{C}=$ total length of grid conductor (m)

$L_{R}=$ total length of ground rods (m)

$E_{S}=$ step voltage $(\mathrm{V})$

$K_{S}=$ mesh factor defined for $\mathrm{n}$ parallel conductor

$L_{S}=$ effective length of $L_{C}+L_{R}$ for step voltage (m)

The results from calculation by all the above formulas were used for drawing the flow chart [11] and designing the ground grid systems of high voltage substations (Figure 3). From the equations 1to 5, GPR can be calculated equivalent to $5.130 \mathrm{kV}$. This GPR value was used for comparing with the results obtained from simulation using the ATP/EMTP and ANSYS (Maxwell) programs. 


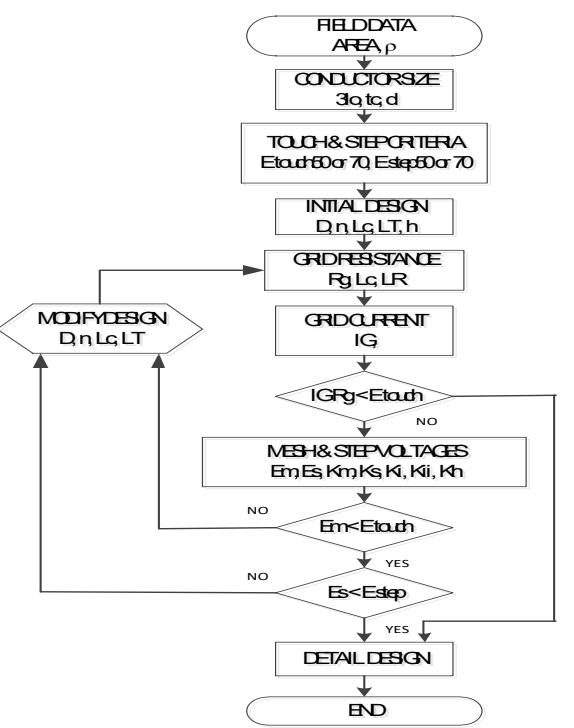

Figure 3. Simulation Flow Chart for Designing the Ground Grid System

\section{GROUND GRID SIMULATIONS}

\subsection{Ground Grid Simulations using ATP/EMTP}

According to the ground grid system (Figure 1), the configuration parameters, and the calculation using simulation flowchart (Figure 3), all resulting parameters were put into the ATP/EMTP software and the process of simulation was started according to the model in Figure 4.

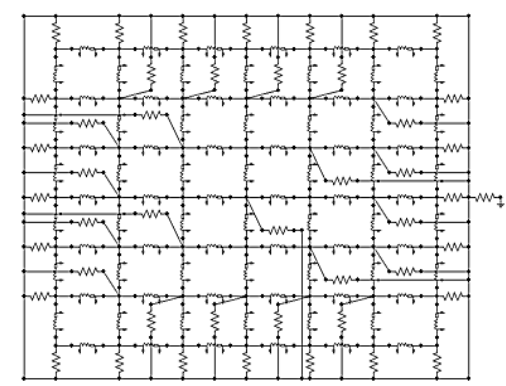

Figure 4. Model of Ground Grid System for ATP/EMTP Program

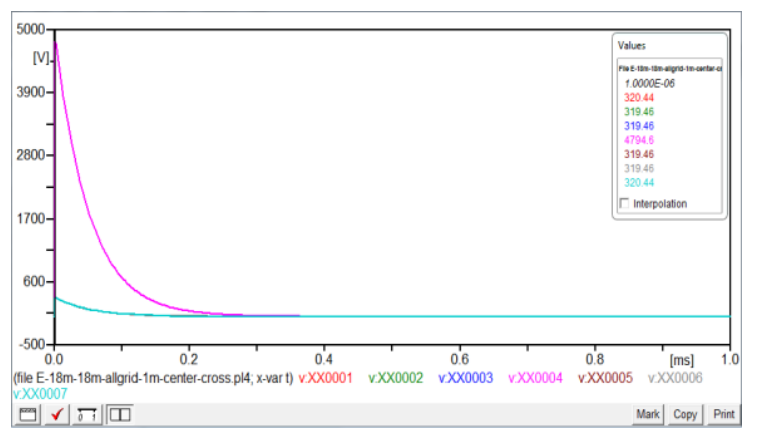

(a)

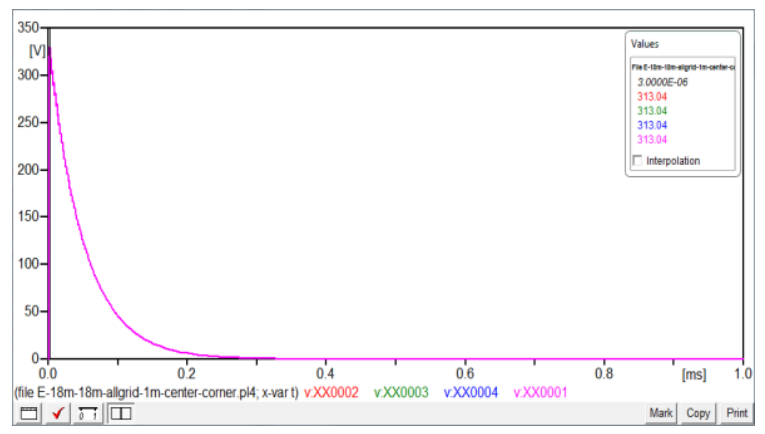

(b)

Figure 5. Voltage Distribution (a) on Diagonal Line and (b) at the Corners of Ground Grid when the Fault Current Being Injected at the Center of Ground Grid 
By ATP/EMTP software, the simulations were processed in case of the $20 \mathrm{kA}$-fault current or the lightning current being injected directly at the center (Figure 5) or at one of the corners (Figure 6) of ground grid. The overvoltage at the four corners and on the diagonal line were measured and plotted as shown in Figures 5 and 6.

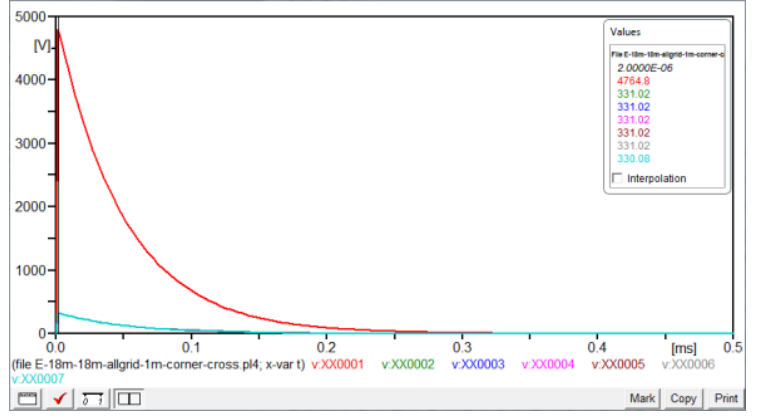

(a)

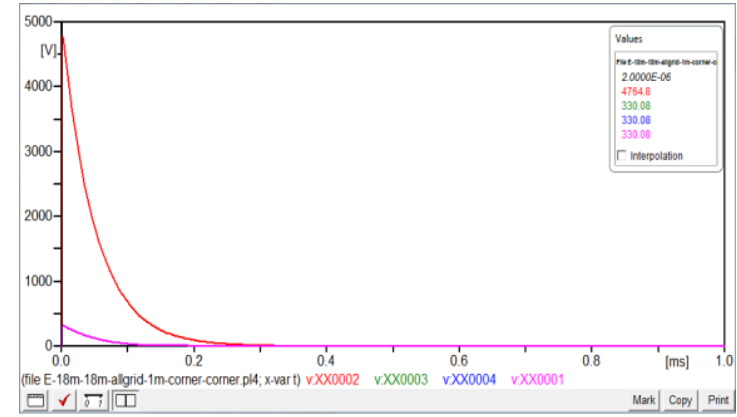

(b)

Figure 6. Voltage Distribution (a) on Diagonal Line and (b) at the Corners of Ground Grid when the Fault Current Being Injected at the Corner of Ground Grid

\subsection{Ground Grid Simulations using ANSYS}

\subsubsection{Case of Single Substation}

The parameters that were calculated in section 2.4 were also processed by ANSYS software. Figure 7 showed the model of a square ground grid connecting with ground rods which was used for simulation process.

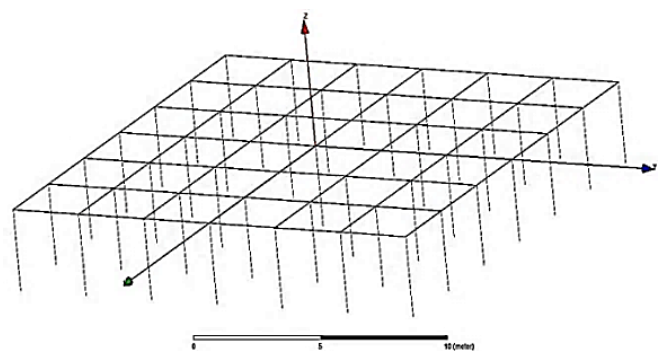

Figure 7. Model of Ground Grid of Single Substation for ANSYS Software

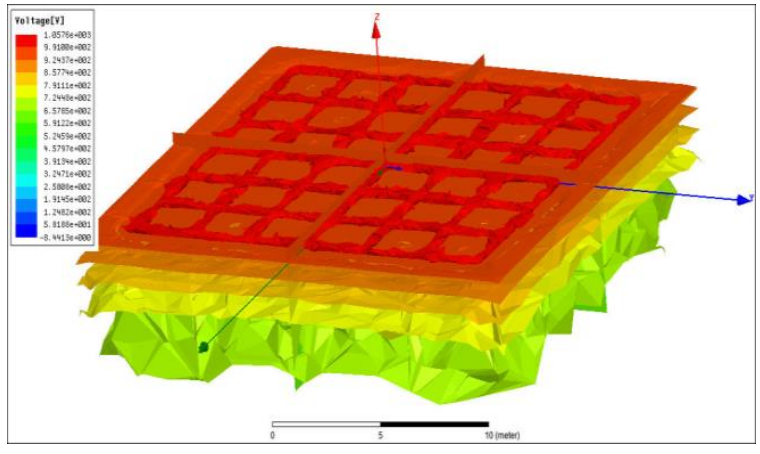

(a)

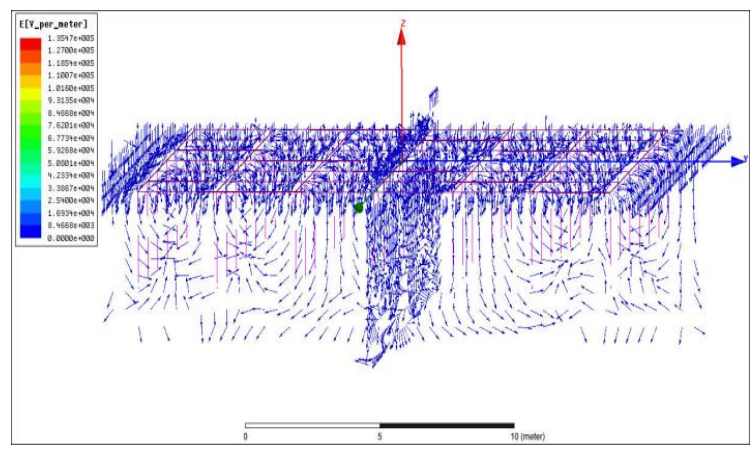

(b)

Figure 8. (a) Voltages and (b) Electric Field Distribution on Ground Grid when Fault Current Being Injected All Over the Surface of Ground Grid 
By ANSYS software, the simulations were performed in case of the $20 \mathrm{kA}$-fault current or the lightning current being injected all over the surface (Figure 8), at the center (Figure 9) or at one of the corners of ground grid (Figure 10). The overvoltage and 3-D electric field distributions on the ground grid were presented in Figures 8 to 10 .

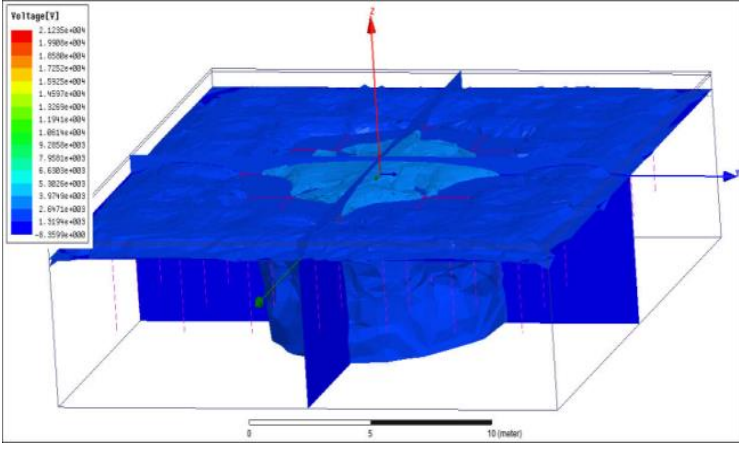

(a)

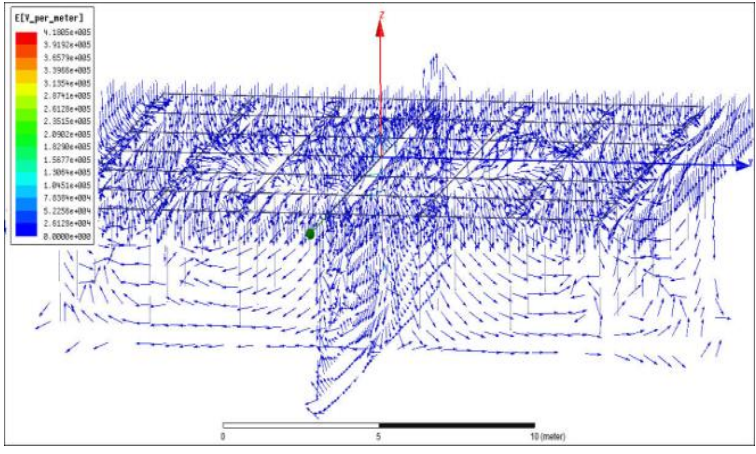

(b)

Figure 9. (a) Voltages and (b) Electric Field Distribution on Ground Grid when Fault Current Being Injected at the Center of Ground Grid

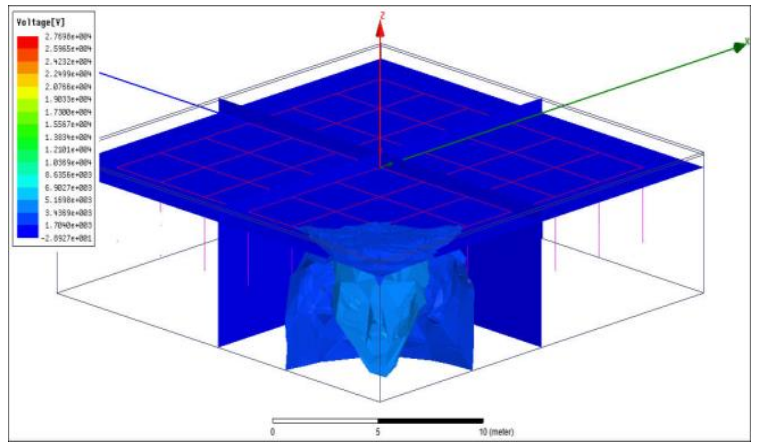

(a)

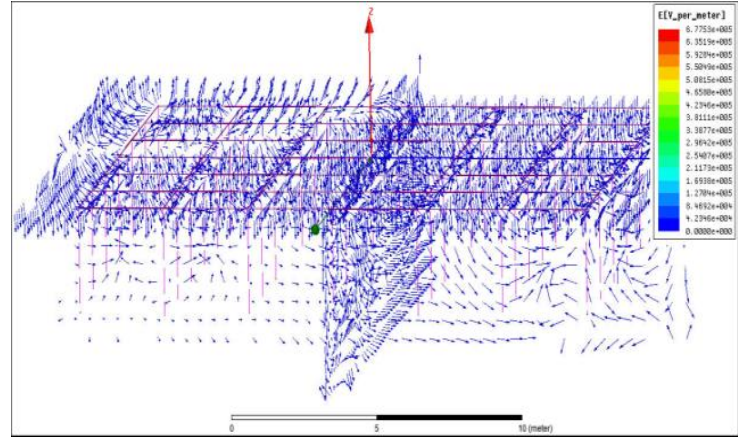

(b)

Figure 10. (a) Voltages and (b) Electric Field Distribution on Ground Grid when Fault Current Being Injected at the Corner of Ground Grid

\subsubsection{Case of Two Neighboring Substations}

The ground grid systems of two neighboring substations, A and B, were investigated similarly to the section 3.2.1. These two substations had the same shape, size and parameters as shown in Figure 11.

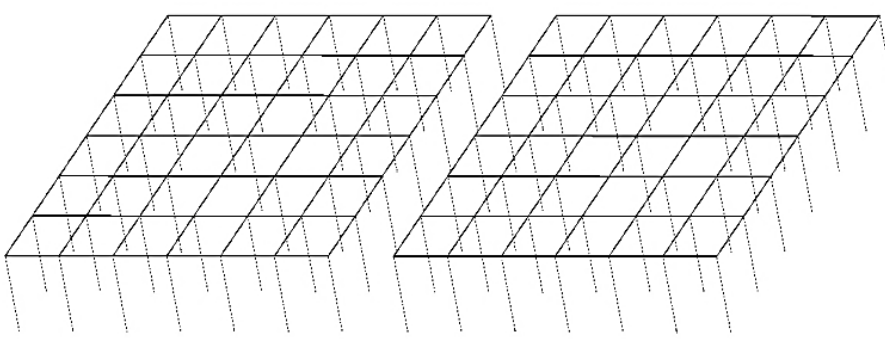

High Voltage Substation A High Voltage Substation B

Figure 11. Model of Ground Grid of Two Neighboring Substationsfor ANSYS Software 
Also, the simulations by ANSYS software were processed in case of the $20 \mathrm{kA}$-fault current or the lightning current being injected all over the surface (Figure 12), at the center (Figure 13), or at one of the corners (Figure 14) of substation A's ground grid. The overvoltage and 3-D electric field distributions of both substations A and B were observed.

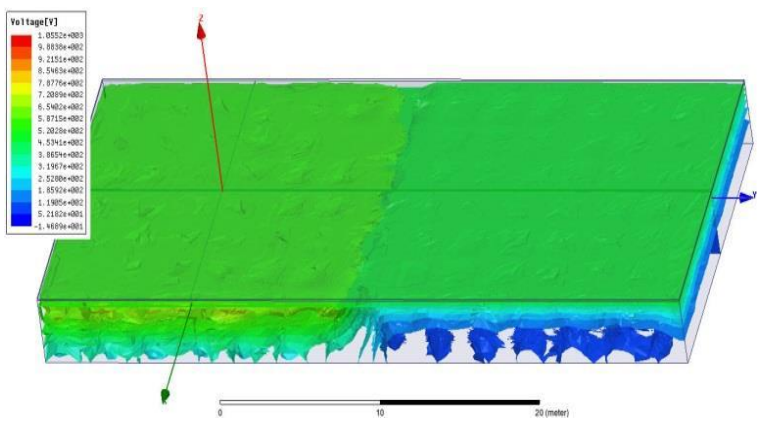

(a)

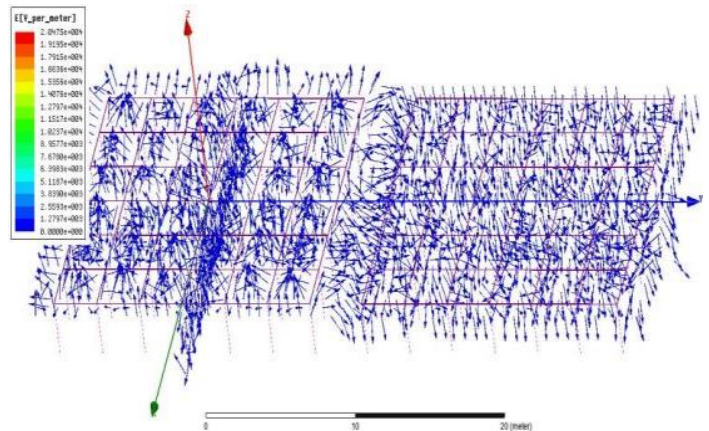

(b)

Figure 12. (a) Voltages and (b) Electric Field Distribution on Ground Grid of Two Neighboring Substations when Fault Current was Injected All Over the Surface of Ground Grid of Substation A

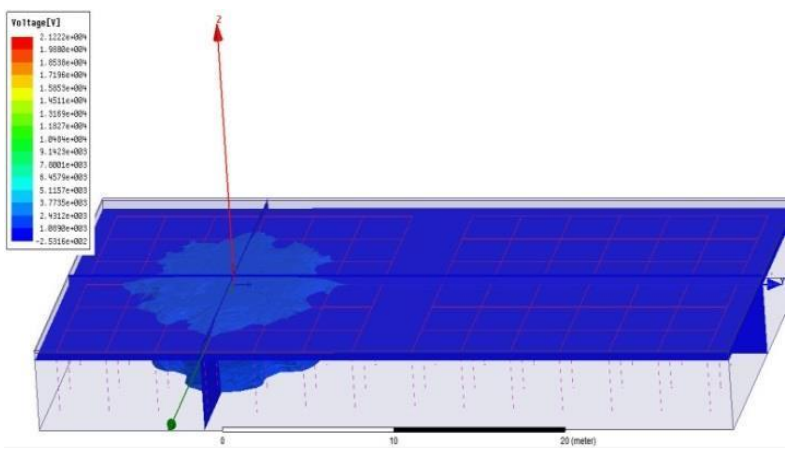

(a)

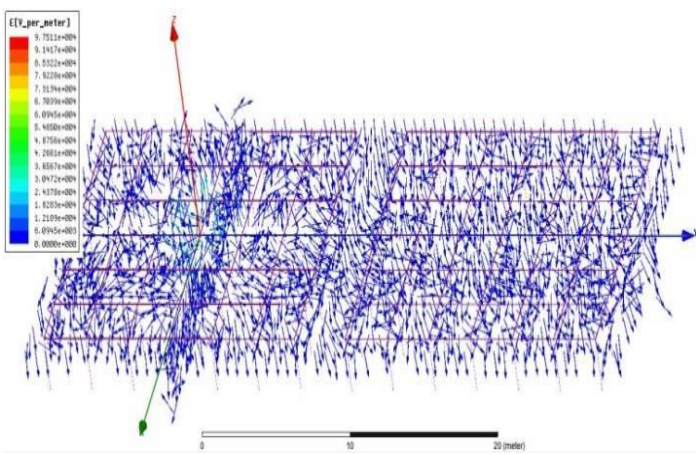

(b)

Figure 13. (a) Voltages and (b) Electric Field Distribution on Ground Grid of Two Neighboring Substations when Fault Current was Injected at the Center of Ground Grid of Substation A

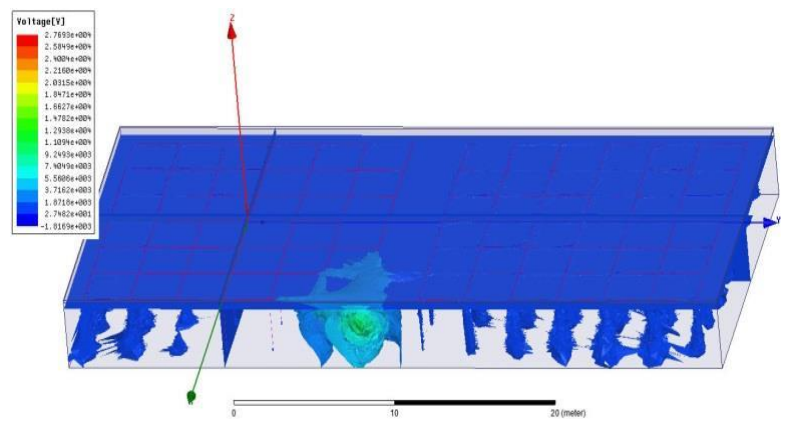

(a)

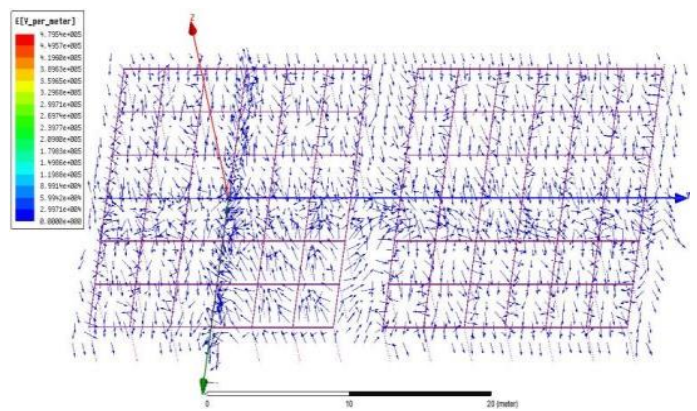

(b)

Figure 14. (a) Voltages and (b) Electric Field Distribution on Ground Grid of Two Neighboring Substations when Fault Current was Injected at the Corner of Ground Grid of Substation A 


\section{RESULTS AND DISCUSSION}

The overvoltage results obtained in Figures 5 to 14 were summarized and shown in Tables 1, 2 and 3.

Table 1. Voltages on Ground Grid when Fault Currents Being Injected at the Center and the Corner of Ground Grid by Simulation Using ATP/EMTP Software

Overvoltage Values that Occurred when the Fault Current Being Injected at the Center and the Corner of Ground Grids

\begin{tabular}{|c|c|c|c|c|c|}
\hline \multicolumn{3}{|c|}{ Voltages that Occurring on Diagonal Line } & \multicolumn{3}{|c|}{ Voltages that Occurring at Four Corners } \\
\hline Node & $\begin{array}{c}\text { Current Being Injected at } \\
\text { the Center } \\
(\mathrm{kV})\end{array}$ & $\begin{array}{l}\text { Current Being } \\
\text { Injected at the Corner } \\
(\mathrm{kV})\end{array}$ & Node & $\begin{array}{c}\text { Current Being } \\
\text { Injected at the Center } \\
(\mathrm{kV})\end{array}$ & $\begin{array}{c}\text { Current Being Injected } \\
\text { at the Corner } \\
(\mathrm{kV})\end{array}$ \\
\hline 0001 & 0.320 & 4.765 & 0002 & 0.313 & 4.765 \\
\hline 0003 & 0.319 & 0.331 & 0003 & 0.313 & 0.330 \\
\hline 0004 & 4.795 & 0.331 & 0004 & 0.313 & 0.330 \\
\hline 0005 & 0.319 & 0.331 & 0001 & 0.313 & 0.330 \\
\hline
\end{tabular}

Table 2. Voltages on Ground Grid at different Underground Depths when Fault Current Being Injected all over the Surface, at the Center and the Corner of Ground Grid of Single Substation by Simulation using

ANSYS Software

Voltages at Different Depths of Ground Grid of Single Substation

\begin{tabular}{|c|c|c|c|}
\hline $\begin{array}{l}\text { Levels of } \\
\text { Depth } \\
\text { (m) }\end{array}$ & $\begin{array}{l}\text { Current Being Injected } \\
\text { All Over the Surface of Ground } \\
\text { Grid } \\
(\mathrm{kV})\end{array}$ & $\begin{array}{l}\text { Current Being Injected } \\
\text { at the Center of } \\
\text { Ground Grid } \\
(\mathrm{kV})\end{array}$ & $\begin{array}{l}\text { Current Being Injected } \\
\text { at the Corner of } \\
\text { Ground Grid } \\
(\mathrm{kV})\end{array}$ \\
\hline 0.1 & 0.991 & 1.319 & 1.704 \\
\hline 0.5 & 1.058 & 3.975 & 5.170 \\
\hline 3 & 0.591 & 1.319 & 1.704 \\
\hline
\end{tabular}

Table 3. Voltages on Ground Grid at different Underground Depths when Fault Current Being Injected at all over the Surface, at the Center and the Corner of Ground Grid of Two Neighboring Substations by

Simulation using A and B ANSYS Software

\begin{tabular}{|c|c|c|c|c|c|c|}
\hline \multirow{3}{*}{$\begin{array}{l}\text { Levels of } \\
\text { Depth } \\
\text { (m) }\end{array}$} & \multicolumn{6}{|c|}{ Voltages at Different Depths of Ground Grid of two neighboring substations A and B } \\
\hline & \multicolumn{2}{|c|}{$\begin{array}{l}\text { Current Being Injected } \\
\text { all over the Surface of Ground } \\
\text { Grid } \\
(\mathrm{kV})\end{array}$} & \multicolumn{2}{|c|}{$\begin{array}{l}\text { Current being Injected } \\
\text { at the Center of } \\
\text { Ground Grid } \\
(\mathrm{kV})\end{array}$} & \multicolumn{2}{|c|}{$\begin{array}{c}\text { Current Being Injected at the } \\
\text { Corner of } \\
\text { Ground Grid } \\
(\mathrm{kV})\end{array}$} \\
\hline & StationA & StationB & StationA & StationB & StationA & StationB \\
\hline 0.1 & 0.587 & 0.453 & 1.089 & 1.089 & 0.027 & 0.027 \\
\hline 0.5 & 0.787 & 0.320 & 3.774 & 1.089 & 3.710 & 0.027 \\
\hline 3 & 0.320 & 0.052 & 1.089 & 1.089 & 0.027 & 0.027 \\
\hline
\end{tabular}

In addition, the values from Tables 2 and 3 were used to plot the graphs in Figures 15 and 16 to compare the results of overvoltage that occurring on the ground grid.

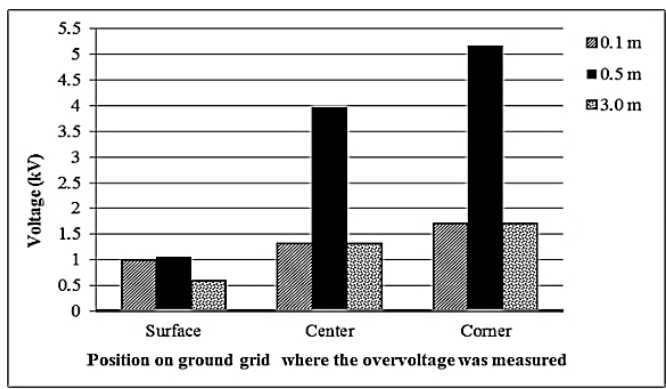

Figure 15. Voltages at Different Depths of Single Substation when Fault Current was Injected at Various Positions

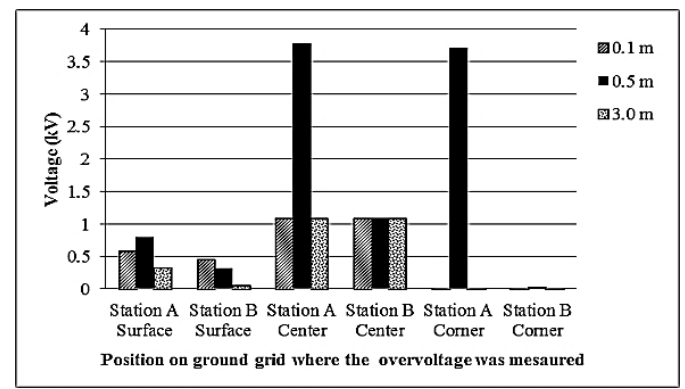

Figure 16. Voltages at Different Depths of Two Neighboring Substations when Fault Current was Injected at Various Positions 
From Table 1, the maximum overvoltage measured diagonally was $4.795 \mathrm{kV}$, which was lower than the calculated GPR $(5.130 \mathrm{kV})$ for $8.346 \%$. In addition, the maximum overvoltage at the corner was $4.765 \mathrm{kV}$, which was lower than the calculation for $7.119 \%$. However, the overvoltage measured in other node areas was as low as approximately $300 \mathrm{~V}$ because, when the overvoltage was distributed down the distance of ground grid and the depth of rods into the earth, the reduction of voltage occurred as shown in Figures 8a, 9a and 10a.

From Table 2 and Figure 8a, when the fault current injected all over the surface of ground grid, the overvoltage was found across the surface of the ground grid and gradually reduced as the depth of ground grid in soil increased. The maximum voltage $(1.058 \mathrm{kV})$ was detected at the depth of $0.5 \mathrm{~m}$, which was much lower than the calculated GPR for $79.38 \%$. This may be because, when the fault current were distributed all over the surface of the ground grid, the electric field vector then distributed uniformly and resulting in the decrease of violence of the overvoltageas shown in Figure 8b. However, at the depth of less than $0.1 \mathrm{~m}$, the overvoltage was much less because of the high resistance of the laydown surface material.

From Table 2 and Figures 9a, 10a and 15, when the fault current were injected at the center and the corner of ground grid, the overvoltage was found to distribute its violence in spherical radius. Also, the electric field vector was found to distribute in circular radius around the center and corner of ground grid as shown in Figures $9 \mathrm{~b}$ and 10b. Furthermore, the overvoltage was found to decrease when the depth of ground grid in soil increased. The maximum overvoltage at the center $(3.975 \mathrm{kV}$, lower than the calculated GPR for $22.516 \%)$ and the corner of ground grid $(5.170 \mathrm{kV}$, higher than the calculated GPR for $0.776 \%$ ) were detected at the depth of $0.5 \mathrm{~m}$. In case of injecting the fault current at the corner of ground grid, the overvoltage was higher than the other cases because the fault current was injected directly into a single point of grid's corner, which resulting in the distribution of overvoltage being limited both horizontally and vertically. The electric field vector had the highest density at the corner of ground grid and tried to leak to a ground grid conductor, which resulting in the maximum violence of overvoltage that was higher than the calculated GPR.

Table 3 and Figures 12a and 16 showed the case of simulation of ground grids located in two neighboring high voltage substations when the fault current were injected all over the surface of substation A. In this case, the overvoltage occurred over all the surface of the ground grid and then reduced according to the depth of ground grid in soil.However, at the depth of ground grid less than $0.1 \mathrm{~m}$, the violence from overvoltage was rather low due to high resistance of the laydown surface material. The maximum voltage $(0.787 \mathrm{kV})$ was detected at the depth of $0.5 \mathrm{~m}$ of ground grid, which was lower than the calculated GPR as much as $84.66 \%$ because the fault current were evenly distributed all over the surface of the ground grid, where the electric field vector also distributed uniformly as shown in Figure $12 \mathrm{~b}$. At the same depth of $0.5 \mathrm{~m}$, the effect of overvoltage on substation B was detected $(0.320 \mathrm{kV})$ and the voltage was lower than calculated GPR for $93.76 \%$. The violence of overvoltage on substation B was much decreased because of the reduction by the ground grid of high voltage substation A, the resistance of soil, and the distance between high voltage substations A andB.

From Figures 13a and 14a, the fault current was injected at the center and the corner of ground grid of substation A, resulting in similar maximum overvoltage at $3.774 \mathrm{kV}$ and $3.710 \mathrm{kV}$, respectively, which were lower than the calculated GPR for $26.44 \%$ and $27.68 \%$, respectively. Their violence was found to distribute in a circle, where the electric field vector also distributed spherically around the center and the corner of ground grid as shown in Figures $13 \mathrm{~b}$ and $14 \mathrm{~b}$. The overvoltage was reduced when the depth of ground grid in soil increased. By injecting the fault current at the center and the corner of ground grid, the maximum overvoltage was detected at the depth of $0.5 \mathrm{~m}(3.774 \mathrm{kV}$ and $3.710 \mathrm{kV})$, which were higher than those caused by injecting the fault current all over the surface of ground grid. This is because the fault current was injected into a single spot of the center or the corner of ground grid, hence resulting in higher violence of overvoltage than injecting the fault current all over the surface of ground grid.

Interestingly, both casesof injecting the fault current at the center and the corner of ground gridin substation A were found to result in similar effects on the high voltage substation B, and having the highest overvoltage on substation B at $1.089 \mathrm{kV}$, which was lower than the calculated GPR for $78.77 \%$. This may be because the fault current was not declined by the ground grid of high voltage substation A, but they gathered into the single spot at the center, thus resulting that a large quantity of the overvoltage could penetrate and be induced to the ground grid of high voltage substation B.

In this study, ATP/EMTP and ANSYS gave the results in similar direction. ATP/EMTP was simple and easier to use and draw and also gave quick processing, but it could be use only to plot graphs of occurredovervolatge values. On the other hand, ANSYS could clearly illustrate the overvoltage and electric field distribution in 3D. This was the first study that applied ANSYS program for 3D simulation to investigate the overvoltage and electric field distribution on ground grids in soilunderneath of both single and two neighboring substations, and also to compare the overvolatage at different depths of underneath soil and 
its gradual decrease due tosoil absorption. Previous study of Liu et al. (2005) showed the model for transient analysis of grounding system under lighning strikes by using FDTD which giving the plotting graphs of overvoltage on ground grids with different sizes. The results showed the levels of voltages per time $(\mathrm{kV} / \mu s)$, but could not illustrate how the overtage distributed through the conductor and soil. When compared among these programs, ANSYS was superior as it could give both calculated values and clear graphical representation of the effect of overvoltage and distribution of electric field in soil.

\section{CONCLUSION}

In this study, it was concluded that in case of the single high voltage substation, the overvoltage was maximum when injecting the fault current at corner of ground grid. However, in case of two neighboring high voltage substations, the overvoltage occurred maximally and was similar between those caused by injecting at the center and at the corner of ground grid. The overvoltage that occurred at the high voltage substation A could permeate through soil and be induced into the ground grid of nearby high voltage substation B, which however depending on the how the fault current were injected at different spots. Additionally, the electric field vector had the highest density at the center and the corners of ground grid substation A and the overvoltage was found to attempt to distribute through the ground grid's conductor and surrounded soil. This overvoltage was then induced into the ground grid of high voltage substation B which reducing its violence to be lower than the case of single high voltage station because the overvoltage was divided and travelled to the substation $\mathrm{B}$. The overvoltage at substation $\mathrm{B}$ caused by injecting the fault current at the center and the corner was higher than those caused by injecting all over the surface. This study could be beneficial to the future design of ground grid systems in both cases of single and two-neighboring substations.

\section{ACKNOWLEDGEMENTS}

The author's gratitude must go to Assistant Professor Dr. Aphibul Pruksanubal at the Department of Electrical and Computer Engineering, Faculty of Engineering, King Mongkut's University of Technology North Bangkok (KMUTNB) for advising this research. The authors also would like to acknowledge "The Sirindhorn International Thai-German Graduate School of Engineering (TGGS)" for providing ANSYS Academic Multiphysics Campus Solution.

\section{REFERENCES}

[1] T. Chardsakul, "Analysis of the grounding system overvoltage in high voltage substation by using ATP draw program”, Electrical Technology \& Electronics, vol. 202, pp. 88-93, January 2009.

[2] F. Menter and L. Grcev, "EMTP-based model for grounding system analysis", IEEE Transactions on Power Delivery, vol. 9, pp. 1838-1847, October 1994.

[3] L.D. Grcev, "Computer analysis of transient voltages in large grounding systems", IEEE Transactions on Power Delivery, vol. 11, pp. 815-823, April 1996.

[4] Y. Liu, M. Zitnik and R. Thottappillil, "An improved transmission line model of grounding system”, IEEE Transactions on Electromagnetic Compatibility, vol. 43, no. 3, pp. 348-355, August 2001

[5] M.I. Lorentzou, N.D. Hatzargyriou, B.C. Papadias, "Time domain analysis of grounding electrodes impulse response", IEEE Transactions on Power Delivery, vol. 18, no. 2, pp. 517-524, April, 2003.

[6] Y. Liu, N. Theethayiand R. Thottappillil, "An engineering model for transient analysis of grounding system under lightning strikes: non-uniform transmission-line approach", IEEE Transactions on Power Delivery, vol. 20, no. 2, pp. 722-730, May 2005.

[7] S.N. Nikolovski, Z. Baus and G. Knežević, "Frequency and time response of power plant grounding system exposed to lightning strike", International Journal of Electrical and Computer Engineering, vol. 6, no. 2, pp.512-525, April 2016.

[8] A.I. El Gayar and Z. Abdul-Malek, "Induced voltages on a gas pipeline due to lightning strikes on nearby overhead transmission line", International Journal of Electrical and Computer Engineering, vol. 6, no. 2, pp. 495-503, April 2016.

[9] A. Phayomhom, S.Sirisumrannukul and T. Kasirawat, "Safety design of ground grid in distribution substation: case study of metropolitan electricity authority's system”, GMSARN International Journal, vol. 4, pp. 67-74, 2010. [http://gmsarnjournal.com/home/wp-content/uploads/2015/08/vol4no2-2.pdf]

[10] An American National Standard, "IEEE guide for safety in AC substation grounding", ANSI/IEEE Std. 80-2000. [http://www.dee.ufrj.br/ acsl/grad/equipamentos/IEEE-std80.pdf]

[11] K. Luewattana, "Effects of overvoltage on ground grid system of high voltage substation", presented at the $12^{\text {th }}$ Int. Conf. Electrical Engineering/Electronics, Computer, Telecommunications and Information Technology (ECTI), Thailand, 2015. 


\section{BIOGRAPHIES OF AUTHORS}

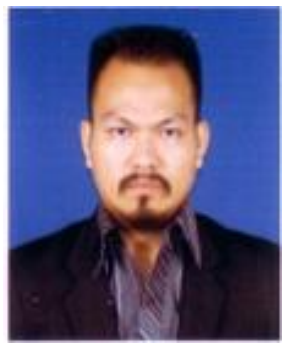

Krung Luewattana. He received the B.Eng. and M.Eng. degrees in Electrical Engineering from Mahanakorn University of Technology (MUT) and King Mongkut's Institute of Technology Ladkrabang (KMITL), Thailand, in 2001 and 2007, respectively. Currently, he is persuing the Ph.D. degree in Electrical Engineering at King Mongkut's University of Technology North Bangkok (KMUTNB). His research interests include high voltage, electrical power system, and enegery conversion.

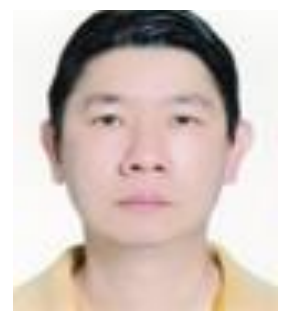

Aphibal Pruksanubal. He received his B.Eng. and M.Eng degrees in Electrical Engineering from Chulalongkorn University (CU), Thailand, in 1996 and 1999, respectively, and Ph.D. degree in Electrical Engineering from Dresden University of Technology (TUD), Germanyin 2005. Currently, he is an Assistant Professor at the Department of ElectricalEngineering, King Mongkut's University of Technology North Bangkok (KMUTNB). His research interests include electromagnetic compatibility and high voltage engineering. 